\title{
Urgências psicológicas no cuidado às mães em casos de abuso sexual intrafamiliar
}

Joana Azevêdo Lima. Faculdade Ruy Barbosa.

Maria de Fátima Pereira Alberto. Universidade Federal da Paraíba.

\section{Resumo}

Este artigo tem como objetivo analisar o discurso das mães de meninas vitimadas pelo abuso sexual intrafamiliar sobre a importância do atendimento especializado para elas que, assim como suas filhas, também foram vitimadas. Esta realidade é entendida à luz da teoria Histórico-Cultural de Vygotsky por meio das categorias teóricas consciência e subjetividade. Trata-se de uma pesquisa qualitativa que usa como instrumento a entrevista semiestruturada. Os discursos são tratados a partir da Análise do Discurso de Bakhtin, considerando-se elementos como enunciado, dialogismo, gêneros discursivos e polifonia. Os discursos revelaram o quanto o abuso sexual é devastador e que as participantes, assim como suas filhas, vivenciam consequências que poderiam ser minimizadas mediante um atendimento especializado, assim como um apoio adequado, o que engloba a participação da família, principalmente a ação protetiva materna. Em sendo elas próprias mães e vítimas, não encontram condições cognitivas e afetivas para lidarem com a vitimação das filhas, reforçando, assim, a importância do atendimento.

Palavras-chave: abuso sexual; atendimento psicológico; mães.

\section{Abstract}

Psychological urges in care for mothers in cases of domestic abuse. This article aims to analyze the discourse of girls' mothers victimized by sexual abuse within the family about the importance of specialized care for them that as their daughters were also victimized. This reality is understood from the theory of Historical-Cultural Vygotsky through theoretical categories of consciousness and subjectivity. This is a qualitative research whose instrument is a semi-structured interview. The speeches are treated from the Discourse Analysis of Bakhtin considering elements such statement, dialogism, polyphony and genres. The speeches reveal how sexual abuse is devastating and the participants as well as their daughters, experience consequences that could be minimized through specialized care as well as adequate support, which includes the participation of the family, especially the maternal protective action. In being victimized themselves and mothers, are not cognitive and affective conditions for dealing with the victimization of children, thus reinforcing the importance of attendance.

Keywords: sexual abuse; psychological care; mothers.

\section{Resumen}

Urgencias psicológicos en la atención de las madres en los casos de violencia doméstica. Este artículo tiene como objetivo analizar el discurso de las madres jóvenes víctimas de abuso sexual dentro de la familia sobre la importancia de la atención especializada para ellas, que al igual que sus hijas, también fueron víctimas. Esta realidad se entiende desde la teoría histórico-cultural de Vygotsky a través de las categorías teóricas conciencia y subjetividad. Se trata de una investigación cualitativa cuyo instrumento es la entrevista semi-estructurada. Los discursos son tratados desde el análisis del discurso de Bakhtin teniendo en cuenta elementos como la declaración, dialogismo, géneros y polifonía. Los discursos revelados como el abuso sexual es devastador y que las participantes, así como sus hijas, experimenten las consecuencias que podrían ser minimizados por un servicio especializado, así como el apoyo adecuado, que incluye la participación de la familia, especialmente a las madres con acción protectora. En ser ellas al mismo tiempo las madres y las víctimas, no encuentran en si mismas condiciones cognitivas y afectivas para hacer frente a la victimización de las hijas, lo que aumenta la importancia de la atención.

Palabras clave: abuso sexual; atención psicológica; madres. 
O abuso sexual intrafamiliar infanto-juvenil é uma forma de violência que tem se tornado motivo central de preocupação da sociedade civil, do governo e também da academia, dada a sua significativa incidência. De acordo com o serviço do Disque-Denúncia Nacional, dos 2.484.755 atendimentos totais realizados desde 2003, quando foi criado o serviço, até 2010, encaminharam-se 130.872 denúncias de violência contra crianças e adolescentes de todo o país. Dessas denúncias, 36\% referem-se à violência sexual. Das denúncias de violência sexual registradas, cerca de $65 \%$ são relativas a abuso sexual infanto-juvenil, e mais de $80 \%$ vitimam meninas (Secretaria de Direitos Humanos da Presidência da República [SDH/PR], 2010). Os dados registrados no primeiro trimestre de 2015 revelam mais de 20 mil denúncias, sendo 4.480 casos de violência sexual contra crianças e adolescentes. Dentre estes dados, 85\% referem a vitimação por abuso sexual e mais da metade dos registros denunciam abuso sexual intrafamiliar (Secretaria de Direitos Humanos da Presidência da República [SDH/PR], 2015).

Nesse sentido, a violência sexual assume expressões de violência de gênero, quando o feminino é o mais vitimado, de acordo com a literatura pesquisada (Furniss, 1993/2002; Lima \& Alberto, 2015) e com os dados do serviço de Disque-Denúncia Nacional (SDH/PR, 2010; SDH/PR, 2015). O abuso sexual entendido como violência de gênero, neste artigo, é compreendido a partir do conceito de patriarcado, donde é estabelecida uma relação de dominação-exploração baseada no poder em que o feminino é o dominado e explorado pelo masculino. Aliado ao patriarcado, o adultocentrismo fortalece essa assimetria entre gêneros, situando o poder nas mãos do masculino adulto (Narvaz \& Koller, 2005; Saffioti, 2004).

Essa assimetria também é evidente em casos de abuso sexual infanto-juvenil na qual uma criança ou adolescente está envolvida numa situação de atividade sexual, ou seja, é usada para gratificação sexual de um adulto ou alguém mais velho (Furniss, 1993/2002). A satisfação sexual de um adulto sobre o corpo de uma criança ou adolescente pode acontecer com ou sem o uso da violência física, por exemplo, desnudar, tocar, acariciar as partes íntimas, entre outros (SDH/PR \& Ministério da Educação [ME], 2004).

Nesse cenário de incidências, a maior parte das denúncias de violência sexual praticada contra crianças e adolescentes refere-se ao tipo intrafamiliar, ou seja, aquele praticado por alguém que a pessoa vitimada considere como parente, podendo esse parentesco ser definido por consanguinidade ou por caráter afetivo (De Antoni \& Koller, 2002; Habigzang \& Caminha, 2004). Mediante o cenário de vitimação de crianças e adolescentes por abuso sexual durante décadas, o Brasil desenvolveu ao longo dos anos uma conscientização social em torno do tema de proteção à infância e à adolescência (Lei n 8069/1990, de 13 de julho de 1990). O país tem se preocupado com a situação de proteção da infância e adolescência e com a garantia de seus direitos, o que levou ao desenvolvimento de estratégias de proteção no que tange a políticas públicas de enfrentamento a esse problema. Surgiram serviços de assistência social especializado como o Centro de Referência da Assistência Social (CRAS) e, sobretudo, na figura do Centro Especializado de Assistência Social (CREAS). Trata-se de um serviço de proteção social especial que proporciona atendimentos direcionados à proteção, monitoramento e redução de ocorrência de riscos, de seu agravamento ou de sua reincidência, por meio de atendimentos continuados a indivíduos e famílias em situação de risco pessoal e social; ou por ocorrência de negligência, abandono, ameaças, maus tratos, violações físicas e psíquicas, discriminações sociais e infração dos direitos humanos. Esse atendimento diferenciado possibilita que os indivíduos ampliem a sua capacidade para enfrentar com autonomia as dificuldades pessoais e sociais existentes (MDS, 2008).

Assim, cabe ao CREAS oferecer atenção especializada de apoio, orientação e acompanhamento a indivíduos e famílias em situação de ameaça ou violação de direitos, o que inclui crianças e adolescentes vitimados pelo abuso sexual, e seus familiares. Portanto, o CREAS se articula com o Poder Judiciário, Ministério Público, Defensoria Pública, Conselhos Tutelares e outras Organizações de Defesa de Direitos, bem como os Hospitais e Institutos Médicos Legais (IML) que também compõem essa rede em suas ramificações, (MDS, 2008).

Nesse contexto de vitimação que envolve também a família, as mães dos vitimados tornam-se alvo das maiores cargas emocionais dentro do processo, uma vez que são elas que geralmente estão mais próximas dos(das) filhos(as). A vivência dessas mães, diante do abuso sexual intrafamiliar praticado contra seus(suas) filhos(as), envolve um sofrimento subjetivo, expresso por elas como culpa e vulnerabilidade social. Além disso, as mães, quando se deparam com a realidade do abuso de seus(suas) filhos(as) tendem a relembrar sua própria vitimação no passado, no caso de, quando crianças ou adolescentes, também terem sido vitimadas. Essa incidência de vitimação em gerações diferentes de uma 
mesma família entende-se como repetição do abuso sexual intrafamiliar infanto-juvenil entre gerações. Diante dessa experiência da vitimação do(s) filhos(as) e delas, a literatura mostra que as mães revelam que sua forma de conduta, algumas vezes, foi baseada nas atitudes de suas mães na época de sua vitimação, o que implica uma repetição de condutas tendo sua mãe como modelo. Basearam-se em seu contexto histórico e cultural para efetivar suas ações, reproduzindo o modo de agir que sua mãe teve diante da revelação de sua própria vitimação no passado (Lima, 2012; Lima \& Alberto, 2015).

É nesse cenário de vivência materna diante da vitimação do(s) filhos(as) e delas mesmas onde se insere o objetivo deste artigo de analisar o discurso das mães de meninas vitimadas pelo abuso sexual intrafamiliar sobre a importância do atendimento especializado para as mães de meninas, que assim como elas, que assim como suas filhas, também foram vitimadas. Para isso serão entrevistadas mães que - além de terem o(s) seu (s) filhos(as) vitimados -, também foram abusadas sexualmente na infância ou adolescência e ao depararemse com a realidade do(s) filhos(as) recordam de sua própria história de vitimação vivenciando subjetivamente as consequências dessa tomada de consciência.

O fato de as mães se recordarem de sua própria vitimação por abuso sexual intrafamiliar, quando ainda eram crianças ou adolescentes, é entendido neste artigo à luz da Psicologia Histórico-Cultural de Vygotsky, a partir das categorias consciência e subjetividade. A consciência se constitui dialeticamente na medida em que o sujeito se relaciona com o outro. O que significa dizer que, para sua constituição, ela depende das condições objetivas e subjetividade do sujeito. É nessa dinâmica dialética entre o sujeito e o outro que a autoconsciência ou autoconhecimento se torna possível, em meio às introspecções e percepções internas experienciadas pelo sujeito, e oportunizadas, nesse contato com o social, com o outro. O mecanismo através do qual se dá essa relação dialética é de ordem reflexa. Nessa ordem reflexa reversível, ambos exercem função de excitante, ou seja, as experiências que cada sujeito tem ao longo de sua vida vão determinar a constituição de sua consciência, uma vez que não existe consciência sem experiência (Vygotsky, 2004).

Vygotsky entendeu a consciência em três dimensões, todas relacionadas com a experiência: experiência histórica (herdada pelo sujeito, não geneticamente, mas sim por meio de suas experiências); experiência social (relacionada com a histórica, revela o componente social do sujeito na relação com o outro); e a experiência duplicada (espécie de planejamento interno, tal como um pensamento antes da ação efetivada) (Vygotsky, 2004, 2009).

Em sendo a consciência o resultado da vivência das experiências, pode-se entender, neste artigo que as reações das mães, ao saberem que o (a) seu filho (a) foi vitimado por abuso sexual intrafamiliar, acontecem no nível de consciência, e são elas que vão regular a forma como agirão também nas situações subsequentes à relação, inclusive, na forma com que vão lidar com as lembranças eclodidas de suas próprias vitimações por abuso sexual intrafamiliar, quando ainda eram crianças ou adolescentes. Isso porque a consciência que o conhecimento do abuso sexual sofrido pelo(a) filho (a) Ihe proporciona é expressa de forma reflexiva de sua própria vitimação.

Essa consciência é que vai proporcionar às mães o modo como compreenderão a situação de vitimação do(a) filho (a) e dela, a forma como ela vai conseguir adaptar-se à situação. A maneira como vai reagir ao tomar conhecimento depende, portanto, de sua condição subjetiva. A subjetividade é entendida por Vygotsky como um processo constante que acompanha as mudanças sócio-históricas do sujeito. Trata-se da constituição do sujeito humano através de sua elaboração do mundo, como suas escolhas, por exemplo, o motivo de alguém pensar ou agir da forma que faz. São exatamente essas condições objetivas que o constituem como sujeito e para isso, novamente, acentua-se o contexto enquanto fator principal nessa constituição (Vygotsky, 2004).

É nesse caminho teórico que é possível uma aproximação aos aspectos particulares e sociais desse sujeito ditados pela forma com que foram internalizados no decorrer das experiências. Entender-se-á, assim, o quão importante se torna o atendimento especializado na vida desses sujeitos, tanto para elaborarem a situação enquanto mães que também se sentem vitimadas e enquanto vitimadas na época de seu próprio abuso quando eram crianças ou adolescentes (Costa, Penso, Rufini, Mendes, \& Borba, 2007; Lima, 2012; Lima, 2015).

\section{Método}

Este artigo baseia-se em dados de uma pesquisa de doutorado realizada pela primeira autora que teve como objetivo analisar a repetição do abuso sexual intrafamiliar feminino entre gerações. Caracteriza-se como uma pesquisa aplicada, do tipo exploratória e de cunho qualitativo. 


\section{Participantes}

As participantes foram selecionadas através de técnica não probabilística do tipo intencional. Para se determinar o número de sujeitos participantes, foi utilizado o critério de saturação, o qual implica a interrupção da realização das entrevistas quando o pesquisador atinge a compreensão da lógica interna do grupo que está estudando, alcança a homogeneidade, a diversidade e a intensidade das informações necessárias ao seu trabalho (Minayo, 1994). Assim, foram realizadas sete entrevistas com mães que tiveram suas filhas atendidas no CREAS por motivos de vitimação pelo abuso sexual intrafamiliar, que possuíam também história de vitimação na infância ou adolescência e que concordaram em participar das entrevistas, mediante consulta prévia da referida instituição. E, como forma de organização, utiliza-se neste artigo o termo Participantes (representadas pela letra P) para designar cada entrevistada.

\section{Técnicas e Instrumentos}

Nesta pesquisa, recorreu-se a entrevistas semiestruturadas que foram realizadas individualmente. O roteiro foi elaborado pelas pesquisadoras e versou sobre a experiência das mães mediante o abuso sexual intrafamiliar sofrido por suas filhas, o conhecimento acerca de outras histórias de vitimação por abuso, sobre o abuso sexual que essas mães sofreram quando crianças ou adolescentes e sobre o modo como elas se sentiram diante dessas duas experiências.

\section{Procedimentos}

Para esta pesquisa, foram adotados todos os passos determinados pela Resolução $N^{\circ} 196 / 96$ do Conselho Nacional de Saúde, vigente à época da realização da pesquisa, assegurando-se os termos éticos necessários. As mães participantes assinaram o Termo de Consentimento Livre e Esclarecido (TCLE), consentindo sua participação na pesquisa.

Para conhecer a experiência das mães que também foram vitimadas pelo abuso sexual infantojuvenil intrafamiliar, foi necessário conhecer no CREAS (enquanto instituição de referência em atendimentos aos casos enfocados) dentre os atendimentos realizados às crianças e adolescentes vitimadas, em quais casos as mães também possuíam tal histórico de vitimação. Então, solicitou-se às técnicas do CREAS que realizassem o contato com as mães e as consultassem acerca de sua concordância em participar da pesquisa sobre violência sexual. Em seguida, a entrevista foi marcada pelas próprias técnicas da instituição na hora e local escolhidos pelas entrevistadas.

\section{Tratamento e Análise dos Dados}

Para tratar os dados, procedeu-se à Análise do Discurso, baseada em Bahktin, através do estabelecimento do corpus, transcrição literal das entrevistas, leitura flutuante. Tomaram-se como elementos: enunciado (unidade da comunicação verbal, produto da interação entre sujeitos), dialogismo (processo de comunicação interativa através do qual um sujeito se vê e se reconhece a partir do outro), polifonia (várias vozes constituintes do discurso) e gêneros discursivos (responsáveis pelo movimento interativo de discursividade existente no discurso) (Bakhtin, 1981).

A análise prioriza os intertextos, o alinhamento e a dinâmica do discurso, buscando verificar o encadeamento das ideias e palavras, o aspecto sequencial apresentado, o estilo, os elementos atípicos e figuras de retórica utilizadas pelas participantes. Em seguida, foram identificados os elementos da análise do discurso e elencadas as falas identificadas como representativas. Ao final, foram realizadas inferências e interpretações com os respectivos intuitos de descrever os dados a partir dos significados obtidos nos discursos e de estabelecer relações com os fundamentos teóricos adotados.

\section{Resultados}

As participantes na época da entrevista tinham idades que variavam entre 33 e 40 anos. Todas tinham emprego formal e quanto à escolaridade, dentre elas uma possuía o primeiro grau incompleto, uma delas tinha o segundo grau incompleto, quatro tinham completado o segundo grau e uma delas estava cursando o supletivo. Das sete Participantes, quatro possuíam relação marital e três estavam separadas. Enquanto mães possuíam de um a quatro filhos, e destes, a filha vitimada por abuso sexual intrafamiliar tinha idade na época do abuso entre quatro e 15 anos: uma delas aos quatro anos, uma aos sete (a mais longa dentre as entrevistadas, durando até 13 anos de idade), duas aos oito anos, duas aos 11 anos e uma delas aos 13 anos. Ou seja, a maioria das filhas das entrevistadas foi vitimada na infância. Já as Participantes, na época que sofreram o abuso sexual intrafamiliar, tinham entre sete e 15 anos de idade: uma delas aos cinco anos, três delas aos sete anos, uma aos oito anos 
(que afirmou ter tido outra vitimação aos 15), uma aos nove anos e uma vitimada aos 10 anos. Quer dizer que todas enunciam suas vitimações terem acontecido na infância, apenas uma delas também ter sido vitimada na adolescência.

Para as enunciações sobre o abuso de sua filha, as Participantes se utilizam predominantemente de polifonia, para trazer as vozes de outras pessoas a fim de construírem a história de vitimação das filhas, pois quando souberam da vitimação das meninas, o abuso já tinha acontecido. Também se utilizam do gênero discursivo narrativo para contarem uma história que se passou, em sua riqueza de detalhes, como envolvidos, local etc.

O fato de comporem enunciações sobre a experiência com detalhes entende-se revelar a necessidade de elaboração da situação através do próprio discurso, demonstrando quanto o mecanismo de tomada de consciência se faz presente no momento não só em que lhes é revelada a situação de vitimação das filhas, mas também na composição da fala de cada uma delas, na enunciação do discurso.

Ao saberem o que aconteceu com as filhas, as Participantes revelam quais as providências que efetivaram assim que tomaram conhecimento. Para esse discurso ser construído, nota-se a necessidade da ajuda de terceiros em tomar decisões como denunciar o abusador e, até mesmo, de como proteger a filha, encaminhando-a para morar longe de casa, com outros parentes ou mesmo num colégio interno.

Essas providências referem o que elas fizeram imediatamente ao saberem da vitimação da filha, no que os discursos revelaram que elas recebem influência direta da forma com que experienciaram essa vitimação no passado, ou seja, enquanto mães tomaram como referência a forma com que suas mães lidaram com a situação. Isso demonstrou o quão importante é a reação materna diante da revelação da vitimação, pois vai influenciar a forma com que decisões futuras serão configuradas. Além disso, essas providências estão também relacionadas com o grau de proximidade dessas mães com o abusador, revelando não somente a dificuldade que tiveram em tomar tal decisão, como, também, o choque e a indignação com a providência imediata de afastamento. $O$ choque pela surpresa de o abusador ser alguém com grau de proximidade elevado pode-se ter como exemplo a fala de P1: "Foi um choque, eu fiquei em estado de choque, né? Que não esperava. Até mesmo pelo fato que a gente vivia bem, tanto ele como eu, né? Vivia bem mesmo. Então pra mim foi uma surpresa".

As participantes enunciam a respeito da indignação frente a situação, o que Ihes levou um afastamento imediato do abusador de suas filhas, como por exemplo, separação do esposo, suposto abusador. Nota-se dentre os efeitos da violência implicações extensas à vida conjugal e afetiva da participante:

Eu me divorciei e vivo a minha vida tranquila. Então 14 anos que assim eu não procuro namorado, não procuro ninguém. Porque foram muitas coisas acontecendo. Veio a infância, aconteceu. Veio o casamento, aconteceu. Depois veio o estrupo ${ }^{1}$ da menina. Então eu tenho uma imagem iergh [expressão não verbal no sentido de repulsa]. Então quando fala de homem... (P7, teve a filha vitimada pelo avô paterno dos sete aos 13 anos de idade, e ela foi vitimada aos sete anos pelo irmão mais velho durante três anos consecutivos).

Quando as Participantes falam sobre os procedimentos tomados diante do conhecimento do abuso sexual sofrido por suas filhas, elas revelam que foram orientadas por parentes e por profissionais da área de defesa dos Direitos das Crianças e dos Adolescentes. Nesses discursos, elas materializam os conhecimentos técnicos com os quais conviveram por conta da vivência do abuso de suas filhas, os quais são reveladores de experiências com a justiça (por exemplo, denúncias, processos) e com a saúde (por exemplo, perícia, exame). Tais procedimentos se referem às decisões mais elaboradas efetivadas e que incluem a rede de proteção. Nesse sentido, as Participantes chegam a construir um discurso em que narram o caminho que percorrem até conseguir atendimento para a filha no CREAS, o que pode incluir hospitais, Instituto Médico Legal (IML), Delegacia, Conselho Tutelar. Nesse cenário, notou-se nos discursos das Participantes o valor ao atendimento psicológico recebido, demonstrando certa satisfação e sentimento de ter sido acolhida na forma que entendem precisar naquele momento, como se pode perceber na fala de P6 que se segue: "...Aí, quando foi pra psicóloga que a psicóloga começou a conversar com ela. Aí, sei que de muito tempo ela começou a dizer..." (P6, a filha foi abusada sexualmente aos oito anos por um vizinho, amigo da família, e ela aos 10 anos também por um vizinho amigo da família).

De acordo com o discurso de P6, entende-se que, para a filha dela, era difícil falar sobre o assunto, dada a complexidade da vivência. Diante desse discurso, pode- 
se compreender que o atendimento da Psicóloga se configurou como um espaço propício para que a menina pudesse revelar a sua vivência de abuso sexual, já que se trata de um profissional que tem um conjunto de técnicas e ferramentas que possibilitam o espaço de acolhimento da demanda adequado.

Embora as Participantes tenham enunciado procedimentos e providências tomadas mediante 0 conhecimento do abuso de suas filhas, estas enunciaram o quão difícil foi agir em meio ao impacto da notícia. Essa dificuldade foi notada quando elas revelaram o seu sofrimento ao saber da vitimação da filha por alguém tão próximo, em que se depositava confiança e que estava acima de suspeitas - o abusador intrafamiliar. $O$ sofrimento também foi expresso por elas como culpa por não terem conseguido protegê-las, como questionamento sobre a qualidade de sua maternagem, e, principalmente, a dificuldade em falar sobre o assunto. Trata-se de um sofrimento vivenciado enquanto mães, mas também como vitimadas, já que, através do conhecimento do abuso sofrido pela filha, essas mulheres reviveram, a partir das lembranças eclodidas, o seu próprio abuso sofrido quando crianças ou adolescentes.

Esse sentimento de culpa, vulnerabilidade e de questionamento enquanto mães, expresso pelas Participantes foi enunciado em seus discursos conforme se pode perceber através da fala de $\mathrm{P} 1$ :

\section{É assim, não sei nem como dizer porque é como eu já disse anteriormente. É uma dor muito grande que a gente sente, entendeu? É... a gente, a gente fica descrente da vida, se perguntando por que com minha filha? Por que isso comigo? Se já aconteceu e tá voltando, mas pra minha filha. Ela tá passando pelo que eu já passei? Eu preferia passar por tudo de novo, tudo de novo ou algo mais, do que ela passar... Certo? (P1, a filha foi abusada sexualmente aos oito anos por um vizinho, amigo da família, e ela aos oito anos por um vizinho e aos 15 por um cunhado).}

Essa fala de P1 nota-se regulada pelo gênero descritivo em que, sob o uso de um coletivo ("a gente") para explicar o que sente, aparece a sua dor, a revivência do sofrimento de vitimação através do abuso da filha, a consciência dialógica de aperceber-se do abuso da filha enquanto repetição em sua família, e do peso que é sofrer um abuso sexual intrafamiliar. Notam-se também materializadas nessa fala as vozes ideológicas de mães que protegem seus filhos e que se dispõem a vivenciar as dores desses para poupá-los.
O sofrimento e dificuldade em falar sobre o assunto do abuso sexual de suas filhas também é motivado pelo fato de elas fazerem relação da experiência com as filhas à sua própria história de vitimação por abuso sexual intrafamiliar. As mães enunciam o fato de não terem recebido proteção na época que sofreram o abuso e, tampouco, terem tido a oportunidade de elaborar o próprio sofrimento. Em meio à ausência de elaboração de sua própria história, elas ainda se deparam com a história semelhante com sua filha, o que as coloca num lugar de revitimadas, provocando sofrimento contundente.

Para elas, relembrar o próprio abuso, a partir de vivências outras de abusos de outrem, significa retomar as vivências da época e reviver os sofrimentos, conforme se pode notar na fala de P1 que se segue:

... Então assim quando eu escuto assim outras pessoas que passam por isso, eu sinto uma dor muito grande dentro de mim. Uma angústia, porque eu me, eu me coloco no lugar daquela pessoa. Me dá aquele desespero na hora de você querer sair e não conseguir e ser abusada, somente, entendeu?...(P1)

A fala de P1 permite perceber que o sofrimento referente às suas vivências de abuso sexual é tamanho que, a cada vez que ela toma conhecimento de qualquer história de vitimação de uma criança ou adolescente por abuso, ela revive a sua própria história. Demonstra o quanto ainda se sente vulnerável ante as situações que envolvem histórias de abuso sexual. Emerge, a partir do discurso, um sujeito que demonstra a sua consciência responsiva diante de cada caso de abuso de que toma conhecimento, revivendo sua vitimação, o que refere dizer que dialogicamente reflete as suas próprias vivências. Nesse discurso, também aparece a questão do poder que o abusador exercia sobre ela, ao enunciar a impossibilidade e incapacidade de se desvencilhar daquele ataque sexual.

Na fala de P1 é possível apreender o discurso que expressa a força dialógica que um acontecimento externo, como o abuso de outra pessoa, é capaz de fazer emergir sentimentos oriundos da memória da própria vitimação. No entanto, o fato de as participantes falarem sobre as suas vitimações no momento da entrevista foi expresso por elas como uma oportunidade de elaboração daquilo que vivenciaram e que não tiveram chance de elaborar.

Esse discurso de entendimento da entrevista como um espaço de elaboração pode ser percebido, por exemplo, através da fala de P4: 
O que eu tenho a acrescentar é que é sempre muito bom quando alguém tem a oportunidade de falar. A agressão, o que passou. Porque isso vai ajudar muito. Ajuda muito e ajudou M [filha de P4] e me ajudou. Só mais isso. (P4, sua filha foi vitimada aos 15 anos pelo pai biológico, e ela foi vitimada aos sete anos pelo primo de seu pai).

O que se apreende do discurso de P4 é que ela atribuiu à entrevista um valor terapêutico e um espaço onde ela pôde elaborar as suas experiências de forma afetiva e cognitiva. Entende-se, ainda, que ela acentua no seu discurso, a importância que tem o atendimento não somente para a criança vitimada, mas também para a sua família, em especial para a mãe.

O abuso sexual que as participantes sofreram é uma experiência que elas não revelaram a ninguém, e que, por isso, não tiveram apoio para a elaboração da situação. Nesse sentido, elas expressam quão sozinhas elas se sentiram em meio a essa vivência e às consequências geradas. $O$ fato de não revelarem a ninguém a sua vitimação na época em que aconteceu torna-se fator central para que não tenham recebido apoio familiar ou atendimento especializado. No entanto, elas enunciam o quanto consideram necessário esse atendimento para a elaboração de suas vivências de sofrimento e dor. Na fala de P2 sobre o atendimento que a sua filha e ela receberam no CREAS, pode-se notar o significado desse apoio especializado:

\begin{abstract}
... Aqui elas [Psicólogas] conversam. Conversaram comigo, conversaram com ela [a filha vitimada]. Então já abriram um pouco mais a mente dela. Ela já, eu já converso com ela, o que acontecer com ela, ela me dizer. Porque já tem contexto com ela e tudo que acontecer com ela, ela contar pra gente, né? Então já com orientação daqui, do CREAS, aí... que eu tenho mais conversado com ela, né. Qualquer coisa que acontecer ela me dizer... entendeu? (P2, a sua filha foi abusada sexualmente aos 11 anos pelo seu cunhado, tio da menina, e ela aos cinco anos por um vizinho, amigo da família).
\end{abstract}

Essa fala de P2 sobre o atendimento recebido pelo CREAS revela o sentido de que foi a partir desse acolhimento que conseguiu lidar com a situação de abuso da filha (conversaram com a filha e com ela), que as orientações recebidas pelas técnicas do local influenciaram em seu relacionamento com a filha (conversam mais). Nota-se, a partir do discurso dela, que o fato de terem conversado com ela também foi importante tanto para ela ser ouvida como sujeito, mulher, como enquanto mãe de menina vitimada por abuso; que, a partir do atendimento no CREAS, conseguiu elaborar-se enquanto sujeito no papel materno e compreender a necessidade de se aproximar da filha. Além disso, ela enuncia nesse discurso o sentido da importância de haver esse tipo de conversa nesses casos de abuso sexual intrafamiliar.

A lacuna provocada pela ausência de apoio, acolhimento ou de credibilidade no serviço dispensado pela rede gerada nas vitimadas é percebida nos discursos em que as mães enunciam a importância do atendimento profissional especializado para as filhas e para elas. Dessa forma, por meio do atendimento ofertado às filhas, elas, enquanto mães, puderam dialogicamente elaborar conteúdos pessoais a respeito de sua própria vitimação por abuso sexual e, inclusive, puderam colocar-se mais disponíveis para ajudar as filhas. Quer dizer que mediante o atendimento que suas filhas receberam elas foram capazes de se perceberem no processo enquanto mães exercendo o papel de acolhimento. No entanto, se elas tivessem recebido o atendimento necessário para elaborar as suas próprias vitimações na época em que aconteceram, poderiam ter se estruturado psicologicamente melhor para ajudar as suas filhas.

Em meio ao atendimento especializado, destacase a importância da Rede de Proteção e a necessidade seu funcionamento efetivo para evitar revitimizações. O caso é que ao buscar-se o serviço especializado de atendimento fatalmente encontram o descompasso ou desalinhamento entre os serviços constituintes da rede. Esse aspecto pode ser percebido através dos discursos das Participantes, mais em destaque de $\mathrm{P} 5^{2}$, que, ao tomar conhecimento do abuso sexual da filha, buscou ajuda, mas precisou peregrinar por três hospitais diferentes, IML, Delegacia, Conselho Tutelar até chegar ao CREAS, onde recebeu atendimento. Pode-se aludir que ela encontrou dificuldades para conseguir atendimento, assim como orientação sobre a vitimização da filha. Embora os locais em que ela tenha buscado atendimento sejam considerados os mais indicados, em casos de abuso sexual, os profissionais que a receberam parecem não estar preparados adequadamente para essa demanda, dada a peregrinação provocada.

\section{Discussão}

Os discursos das Participantes tornam possível uma aproximação de duas realidades: a vitimação de abuso sexual intrafamiliar quando eram crianças e também a experiência de vitimação de suas filhas. Tais experiências sociais são constituintes destas enquanto sujeitos ao longo da vida. 
O discurso materializado indicou que para além do abuso sexual intrafamiliar e vitimação, as experiências foram marcadas por características como a vulnerabilidade da criança, a responsabilidade do adulto responsável por ela naquele contexto, o acesso facilitado que um abusador que convive com a família da vitimada tem sobre ela. Esta caracterização envolve discussão acerca do patriarcado, assimetria de poder e adultocentrismo. As consequências da vitimação por abuso sexual, segundo Habigzang e Koller (2006), são entendidas como impactos compostos por três fatores como provocadoras de consequências que ultrapassam àquelas geradas pelo abuso sexual em si (tempo de duração, parentesco com o vitimador, como foi a reação dos demais familiares e se há a presença de outras formas de violência) o que inclui impactos relacionados a fatores intrínsecos (vulnerabilidade e resiliência) e extrínsecos (rede de apoio social e afetivo).

Em famílias que experienciaram situações de abuso sexual intrafamiliar, as mães tendem a acreditar em suas filhas e a buscar a proteção que julgam necessária (Furniss, 1993/2002). Nesse sentido, Santos, Pelisoli e Del'Aglio (2012) analisam que o apoio familiar se torna fator imprescindível para o encaminhamento da situação de violência vivenciada pela criança (ou pelo adolescente) vitimada. O papel da mãe recebe especial destaque devido ao significado importante na manutenção da sensação de proteção de seu (sua) filho (a).

No entanto, mães que vivenciaram essa situação, através de sua vitimação e a de sua filha, não encontram em si mesmas condições suficientes para lidar com a situação das filhas, por terem que admitir que sofrimento semelhante ao seu foi infligido à menina, o que justifica a necessidade e a busca pelo atendimento especializado, assim como pelo apoio de membros da família. Os discursos refletem que as vivências subjetivas maternas envolveram um sofrimento subjetivo, expresso por elas como culpa por não terem protegido as filhas dessa vitimação e que as mobiliza de tal maneira, ao ponto de fazê-las rememorar as lembranças de seu próprio abuso no passado, quando eram crianças ou adolescentes, dado o sofrimento vivido (Lima, 2012; Lima \& Alberto, 2015).

Esse processo em que as mães se lembram de seus abusos a partir do abuso das filhas, para a Análise do Discurso, acontece dialogicamente na medida em que elas interagem com a realidade das filhas (Bakhtin, 1981). E enquanto sujeitos constituídos de suas relações sociais dialéticas que são, a consciência que tem de suas filhas e das suas vitimações torna possível a autoconsciência utilizando-se das introspecções e percepções internas experienciadas (Vygotsky, 2004). Esse processo de conhecimento de si mesma, em que as Participantes podem acessar conteúdos de vivências com que não mais tinham contato oportunizado a partir da relação dialética, é denominado na Teoria HistóricoCultural como autoconsciência ou autoconhecimento. É o despertar de uma vivência passada que ao retornar obriga a tomada de consciência (Vygotsky, 2009), como foi o que aconteceu com o abuso sexual que elas sofreram. É o colocar-se no lugar do outro e se ver na situação, processo em que as Participantes entram em contato consigo através da introspecção. $\mathrm{O}$ acesso a esses conteúdos internos que compõem a autoconsciência das Participantes foi exercido pelo próprio abuso sexual que suas filhas sofreram. A partir deles, veio à tona o conteúdo de suas vivências de vitimação por abuso. Esses conteúdos também foram acessados por meio da entrevista realizada, que as fez recuperar essa experiência através das vivências subjetivas.

A partir dos discursos das Participantes, pode-se notar o sofrimento delas mediante a experiência de vitimação por abuso sexual intrafamiliar na infância e também a dificuldade em revelar à mãe o que lhe aconteceu na época, evidenciando a não elaboração da experiência e dos sentimentos gerados no contexto. Esse sofrimento foi enunciado em meio a um discurso que revelava a carência que sentiam por não terem recebido o acolhimento que julgam necessário ou o atendimento profissional especializado. De acordo com Penso e Neves (2008) e Costa et al. (2007), é nos serviços sociais existentes que as vítimas podem encontrar meios de construir em si estrutura necessária para lidar com essa situação de abuso. Nos discursos analisados, as Participantes frequentemente enunciavam que tinham dificuldade em verbalizar a situação, e, para isso, elas se utilizavam de vozes de outros sujeitos com os quais vivenciaram a situação de vitimação tanto das filhas como delas mesmas no passado. Refere dizer que, para contarem as histórias, as Participantes precisaram das vozes de outros que também participaram da situação, como irmãos, cunhados, vizinhos, amigos, filhos (o que inclui a filha vitimada e os irmãos) etc. A isso se analisa ser motivado pelo fato também de elas terem tomado conhecimento da vitimação das filhas através de outrem, não tendo desconfiado antes, sendo, então, surpreendidas com a informação. Nesse sentido, além da polifonia que se fez presente, os discursos também se caracterizaram por apresentarem o gênero narrativo, no auxílio de contar a história. O gênero narrativo foi 
utilizado por elas para contar detalhes da forma como tudo aconteceu, como envolvidos, lugar, horário etc.

Esse atendimento materno se torna imprescindível para a elaboração familiar acerca da experiência de abuso intrafamiliar da menina, já que envolve toda a família, pois é nesses espaços que elas tendem a sentirse acolhidas e se permitem pedir ajuda para si e para sua família, admitindo que precisam de apoio. Nesse contexto, as mães podem, inclusive, revelar que há muito tempo esse auxílio Ihes era necessário (Costa et al., 2007; Santos et al., 2012).

O modo como as Participantes agem ou pensam, diante das experiências de vivência do abuso sexual sofrido por suas filhas, da vivência de vitimação por abuso sexual quando crianças, assim como da experiência provocada pela entrevista sobre essas vivências, pode ser entendido através da subjetividade. Ou seja, cada experiência dessas que elas tiveram as constituiu enquanto sujeitos e, portanto, faz parte de sua subjetividade. E cada vivência dessas gerou níveis de consciência para elas, assim como aconteceu em relação à necessidade de atendimento especializado enunciado. Quer dizer que a tomada de consciência aconteceu em momentos distintos de compreensão da realidade, associada à vivência subjetiva, que ganhando diferente sentido, revelando o novo nível de consciência acerca da experiência de abuso sexual intrafamiliar: na época em que foram vitimadas por abuso sexual intrafamiliar, quando tomaram conhecimento do abuso das filhas e quando estavam elaborando seus discursos durante a entrevista. E, em todas essas experiências, as Participantes sinalizaram a necessidade de atendimento especializado e os prejuízos vivenciados por quem não os teve.

O funcionamento do atendimento especializado em rede às vítimas do abuso sexual aponta fatores de ordem social, institucional e legal que tendem a banalizar, negligenciar, confundir e postergar as aplicações de medidas de proteção às vítimas (Habigzang \& Koller, 2006; Lima, 2012; Lima \& Alberto, 2015; Penso \& Neves, 2008); aspectos esses que participam da revitimação e acréscimo dos danos causados pela violência em si. Nesse sentido, a rede de atenção às crianças mostra-se descontínua, fragmentada, interrompida, sem vinculação entre suas partes.

\section{Considerações finais}

O abuso sexual intrafamiliar infanto-juvenil assume sua complexidade em dimensões sociais, psíquicas, econômicas, políticas e históricas. É uma forma de violência que atinge toda a família, situando os seus membros no lugar de vitimados. Nesse cenário, a mãe das meninas vitimadas recebem grande carga emocional, e a elas é debitada a responsabilidade de cuidado e proteção, reafirmando as características históricas de socialização.

A análise dos discursos das Participantes permitiu conhecê-las subjetivamente, revelando sujeitos que se constituíram na vulnerabilidade e sofrimento das vivências de abuso sexual intrafamiliar que incidiram em sua família em diferentes gerações. Sujeitos que vivenciam cognitiva e afetivamente as lembranças de seu próprio abuso. Ou seja, dialogicamente, elas revivem as suas vitimações a partir do conhecimento de uma história de abuso sexual que lhes chega.

Segundo as Participantes, a vivência de suas vitimações no passado serviu de base para as vivências, providências e os procedimentos efetivados diante do conhecimento do abuso sexual intrafamiliar sofrido pela filha. Significa dizer que puderam reviver a fragilidade e falta de proteção da infância, quando foram abusadas sexualmente por alguém da família. $\mathrm{E}$, neste sentido, a tomada de consciência, mediante o conhecimento do abuso de suas filhas, Ihes constitui um sujeito que se percebe na vulnerabilidade e no sofrimento enquanto mãe, mulher e vitimada no passado. Um sujeito vitimado por suas próprias lembranças e pelo próprio desconhecimento de ações protetivas, portanto, de seu potencial de protetora de suas filhas.

As Participantes destacam em seus discursos a importância de espaços de escuta e atendimento das famílias de crianças e adolescentes abusados sexualmente, em especial, a necessidade desse cuidado com as mães, as quais podem ter histórias de vitimação também por abuso sexual no passado e que necessitam, portanto, de ajuda para poder constituir-se agente protetivo da filha.

Nesses casos, faz-se importante que os profissionais sejam capacitados de forma a compreender a complexidade da situação de abuso sexual intrafamiliar e, mais ainda, da repetição intrafamiliar desse abuso entre gerações da mesma família. Isso porque estarão diante de uma família vitimada que necessita de uma escuta especializada e de ações que lhes proporcionem a saída desse estado de vitimação.

\section{Referências}

Bakhtin, M. (1981). Marxismo e filosofia da linguagem (2 $2^{\underline{a}}$ ed.). São Paulo, SP: Hucitec. 
Costa, L. F., Penso, M. A., Rufini, B. R., Mendes, A. de A., \& Borba, N. F. (2007). Família e abuso sexual: silêncio e sofrimento entre a denúncia e a intervenção terapêutica. Arquivos Brasileiros de Psicologia, 59(2), 245-255. Recuperado de http://pepsic.bvsalud.org/pdf/arbp/ v59n2/v59n2a13.pdf

De Antoni, C., \& Koller, S. H. (2002). Violência doméstica e comunitária. In M. L. J. Contini, S. H. Koller, \& M. N. S. Barros (Orgs.), Adolescência e Psicologia: concepções práticas e reflexões críticas (pp. 85-91). Rio de Janeiro: Conselho Federal de Psicologia.

Furniss, T. (2002). Abuso sexual da criança: uma abordagem multidisciplinar: manejo, terapia e intervenção legal integrados. Porto Alegre, RS: Artmed. (Obra original publicada em 1993)

Habigzang, L. F., \& Caminha, R. M. (2004). Abuso sexual contra crianças e adolescentes: conceituação e intervenção clínica. São Paulo: Casa do Psicólogo.

Habigzang, L. F., \& Koller, S. H. (2006). Terapia cognitivo-comportamental e promoção de resiliência para meninas vítimas de abuso sexual intrafamiliar. In D. D. Dell'Aglio, S. H Koller, \& M. A. M. Yunes (Orgs.), Resiliência e psicologia positiva: interfaces do risco à proteção. (pp. 233-258). São Paulo: Casa do psicólogo.

Lei $n^{\circ} 8069 / 1990$, de 13 de julho de 1990.(1990, 13 de julho). Dispõe sobre o estatuto da criança e do adolescente. Diário Oficial da União, seção 1.Recuperado de http://www.planalto.gov.br/ccivil_03/leis/L8069.htm.

Lima, J. A. (2012). A repetição do abuso sexual intrafamiliar infantojuvenil entre gerações (Tese de Doutorado). Universidade Federal da Paraíba, João Pessoa, PB. Recuperado de http://tede.biblioteca. ufpb.br:8080/handle/tede/6901

Lima, J. A., \& Alberto, M. de F. P. (2015). O olhar de mães acerca do abuso sexual intrafamiliar sofrido por suas filhas. Psicologia: Ciência e Profissão, 35(4), 1157-1170. doi: 10.1590/1982-3703001692013

Minayo, M. C. de S. (1994). O desafio do conhecimento: pesquisa qualitativa em saúde ( $3^{\underline{a}}$ ed.). São Paulo: Hucitec-Abrasco.

Ministério do Desenvolvimento Social e Combate à Fome (2008). SUAS: configurando os eixos de mudança. Brasília, DF: Instituto de Estudos Especiais da Pontifícia Universidade Católica de São Paulo.
Narvaz, M. G., \& Koller, S. H. (2005). Reflexões sobre o atendimento de meninas e mulheres vítimas de violência. Novas Abordagens em Direitos Humanos: enfrentamento à Violência, 1(1), 34-42.

Penso, M.A., \& Neves, V.L.(2008). Abuso sexual infantile transgeracionalidade. In M. A. Penso \& L. F. Costa (Orgs.), A transmissão geracional em diferentes contextos: da pesquisa à intervenção. (pp. 123-142). São Paulo: Summus

Saffioti, H. I. B. (2004). Gênero, patriarcado e violência. São Paulo, SP Fundação Perseu Abramo.

Santos, S. S., Pelisoli, C., \& Del'Aglio, D. D. (2012). Desvendando segredos: padrões e dinâmicas familiares no abuso sexual infantil. In L. F. Habigzang \& S. H. Koller (Orgs.), Violência contra crianças e adolescentes: teoria, pesquisa e prática. (pp. 55-68). Porto Alegre: Artmed.

Secretaria Especial dos Direitos Humanos da Presidência da República \& Ministério da Educação (2004). Guia escolar: métodos para identificação de sinais de abuso e exploração sexual de crianças e adolescentes. Brasília: Autor.

Secretaria Especial de Direitos Humanos da Presidência da República (2010). Disque denúncia nacional de abuso e exploração sexual contra crianças e adolescentes - 100. Recuperado de http://www.prac.ufpb.br/copac/escolaqueproteje/documentos/ FEPETIPB_241110/FEPETIDD.pdf

Secretaria Especial de Direitos Humanos da Presidência da República (2015). Disque denúncia nacional de abuso e exploração sexual contra crianças e adolescentes - 100. Recuperado de http://www. sdh.gov.br/noticias/2015/maio/disque-100-quatro-mil-denuncias-deviolencia-sexual-contra-criancas-e-adolescentes-foram-registradasno-primeiro-trimestre-de-2015

Vygotsky, L.S. (2004). Teoria e método em psicologia. (3 $3^{\text {a }}$ ed., C. Berliner, Trad.). São Paulo: Martins Fontes. (Obra Original publicada em 1982)

Vygotsky, L. S. (2009). A construção do pensamento e da linguagem. (2 $2^{\mathrm{a}}$ ed., P. Bezerra, Trad.). São Paulo: Martins Fontes

\footnotetext{
${ }^{1}$ Todas as transcrições de entrevistas apresentadas neste artigo são literais, portanto há a presença de termos gramaticalmente incorretos.

${ }^{2}$ Foi vitimada aos cinco anos por seu padrasto e teve três dentre os quatro filhos vitimados também um por seu padrasto, por um vizinho (amigo da família)

e uma das filhas foi vitimada por abuso sexual extrafamiliar.
} 
J.A. Lima, M.F.P. Alberto

Joana Azevêdo Lima, Doutora em Psicologia Social pela Universidade Federal da Paraíba (UFPB) com estágio sanduíche na Universidad Complutense de Madrid (UCM/Espanha), é Professora da Faculdade Ruy Barbosa (FRB/Devry/Brasil). Endereço para correspondência: Rua Theodomiro Baptista, 422, Campus Rio Vermelho, Salvador/ BA. CEP: 41940-320. Telefone (71) 4020-4900. E-mail: joanaazevedolima@yahoo.com.br

Maria de Fátima Pereira Alberto, Doutora em Sociologia pela Universidade Federal de Pernambuco, Pós-Doutorado em Psicologia pela Universidade Federal do Rio Grande do Norte (UFRN), é Professora Associado IV no Departamento de Psicologia e Programa de PósGraduação em Psicologia da Universidade Federal da Paraíba (UFPB). E-mail: jfalberto@uol.com.br 